\title{
ANÁLISIS DE LOS DISCURSOS DE ECUADOR EN LA ORGANIZACIÓN DE NACIONES UNIDAS PERIODO 2007-2016
}

Analysis of Ecuador's Discourses in the Organization of United Nations Period 2007-2016

\author{
JUAN ARTURO MILA-MALDONADO \\ Facultad Latinoamericana de Ciencias Sociales \\ arturomila2@gmail.com \\ ANDERSON DAVID CARLOSAMA-LECHON \\ Facultad Latinoamericana de Ciencias Sociales \\ andcarlosamafl@flacso.edu.ec \\ ANDREA MILA-MALDONADO \\ Universidade Santiago de Compostela \\ andreadelcarmen.mila@rai.usc.es \\ DIANA CAROLINA PABÓN-VALENZUELA \\ Facultad Latinoamericana de Ciencias Sociales \\ dicpabonfl@flacso.edu.ec
}

Resumen. El presente artículo tiene como objetivo analizar los discursos realizados por Ecuador en el marco de la Asamblea General de la Organización de Naciones Unidas durante el periodo 2007-2016, identificando las principales categorías discursivas propuestas por este país desde la perspectiva de contra-hegemonía. Se parte de la metodología mixta con énfasis en el enfoque cualitativo a través del método comparado y analítico. Para el análisis se construyó una matriz ad hoc que incluye las principales variables y categorías. Como principales resultados se identificó la preeminencia de temáticas políticas y sociales, alternancia de actor principal entre representantes del Ejecutivo (presidente, vicepresidente y Canciller) y delegados y representantes que siguen una misma línea discursiva crítica, la identificación de Estados Unidos, FMI, BM, CIADI como adversarios políticos y la predominancia del uso de las siguientes categorías: democracia representativa y Buen Vivir. Palabras clave: Análisis de discurso; Revolución Ciudadana; contra-hegemonía; ONU

\begin{abstract}
This article aims to analyze the discourses made by Ecuador in the framework of the General Assembly of the United Nations Organization during the period 20072016, identifying the principal discursive categories proposed by this country from a counter-hegemonic perspective. It is based on the mixed methodology with emphasis on the qualitative approach through the comparative and analytical method. For the analysis, an ad hoc matrix was built that includes the main variables and categories. The principal results were the preeminence of political and social issues, alternation of main actor between representatives of the Executive (President, Vice President and Chancellor) and delegates and representatives that follow the same critical discourse line, the identification of United States, (IMF, WB, ICSID) as political adversaries and the predominance of the use of the following categories: representative democracy and Buen Vivir.
\end{abstract}

Keywords: Critical Discourse Analysis; Revolución Ciudadana; contra-hegemonía; UN. 


\section{INTRODUCCIÓN}

La hegemonía de Estados Unidos en América Latina ha determinado en gran medida, los lineamientos de las agendas de política exterior de los países de la región. Desde la primera década del siglo XXI, esta situación, que si bien no se ha modificado totalmente, ha mostrado cambios sustanciales en la relación de los países con la potencia hegemónica: fortalecimiento de las relaciones Sur-Sur; diversificación de socios políticos y comerciales; construcción de un discurso en los términos de contra-hegemonía, mayor campo de acción de los actores sociales en la construcción de políticas públicas top down, entre otras. Dentro de este contexto, destaca la irrupción de Hugo Chávez quien es considerado el predecesor de algunos gobiernos de izquierda que orientaron su discurso al socialismo o socialismo del siglo XXI (Serbin, Martínez y Ramanzini, 2012). Es así que, en concordancia con la transición que experimentaba la región, Ecuador dio un giro ideológico hacia la izquierda de la mano de Rafael Correa a partir del año 2007, gobierno que se manejó bajo una política pos o anti-neoliberal y de tensión de las relaciones políticas con Estados Unidos e instituciones financieras internacionales - FMI, BM -que afectaron la economía de este país. Es por ello que, en el ámbito exterior, la llamada Revolución Ciudadana propuso una nueva agenda que incluye como ejes prioritarios el multilateralismo, la cooperación Sur-Sur (Zepeda y Egas, 2011) y la diversificación de socios políticos y comerciales.

El nuevo programa de gobierno se consagró mediante la Constitución de Montecristi en octubre de 2008, que orientó el Plan Nacional de Desarrollo 2007 - 2010, el Plan Nacional del Buen Vivir 2009 - 2013 y el Plan Nacional del Buen Vivir de 20132017. Las primeras acciones de gobierno de Rafael Correa fueron la declaración de la deuda externa adquirida por gobiernos anteriores como ilegítima y odiosa; la expulsión de agregados diplomáticos de la sede diplomática de Estados Unidos, la no renovación del tratado sobre la base de Manta, y otros que colocaron de relieve la postura contrahegemónica de este gobierno. El presente estudio analiza aspectos referidos a su discurso en el ámbito internacional.

\section{MARCO TEÓRICO}

\subsection{El discurso. Una visión teorética y metodológica}

El análisis de discurso se constituye como una base metodológica a través de la cual es posible deconstruir a un individuo o entidad desde su uso del lenguaje como elemento de persuasión, transmisión de preceptos ideológicos y mensajes diversos. Este método permite vislumbrar los propósitos implícitos en el habla y la escritura. En este orden, se habla de una 'lingüística crítica', que bien podría partir de las bases de la teoría crítica, de la escuela de Frankfurt (Van Dijk, 1999). Este subcampo de investigación cualitativo se denomina como Análisis Crítico del Discurso (ACD) (Van Dijk, 2016), en tanto parte de la necesidad de comprender la estrecha relación entre el poder y el uso del lenguaje, manifiesto a través de discursos hegemónicos de dominación que presentan una serie de efectos en, habitualmente, grandes audiencias. El ACD no se constituye en sí como un método, sino que incorpora ciertos atributos interdisciplinarios del ámbito cualitativo para estudiar las implicaciones detrás del empleo de ciertos elementos discursivos en el campo de las ciencias sociales, políticas y la comunicación. Los Estudios Críticos del 
Discurso, - elemento macro del cual se deriva el encuadre investigativo del análisis de estas composiciones lingüísticas -, se constituyen como principios y teorías interdisciplinarias que incluyen distintos enfoques de interpretación en el nivel micro y macro discursivo, cuya reflexión se orienta a problemáticas de relevancia social, política y cultural (Pardo, 2012).

Dado su enfoque interdisciplinar, el Análisis Crítico del Discurso permite comprender efectos cognitivos producidos por simbolismos articulados de forma deliberativa por el emisor inicial del mensaje. Este constructo incorpora elementos de percepción de realidad compartidos entre las partes, o al menos manifiesta la base para la agregación de nuevos conceptos sobre los cuales interactúan figuras de poder con miembros de un grupo o comunidad. En tal sentido, "el compromiso ético del investigador es reconocer la multiplicidad de formas de dominación que se expresan en los discursos" (Pardo 2012, 44).

Para Valencia (2011), analizar un discurso es también buscar comprender la ideología que lo moviliza, en tanto no se analiza el empleo de la lengua como el conjunto de vocablos empleados para construir un sistema de codificación, sino que también se evalúa su componente social de intercambio de experiencias y significados consensuados entre los individuos. Así, al hablar del ACD, es necesario que entender que se fundamenta en entender la "forma y a la vez función" (p. 146); es decir, cómo se compone el mensaje y bajo qué propósito a la par de que se busca distinguir la veracidad y la falsedad condicionante del tal constructo social.

\subsection{Liderazgo Político}

El liderazgo político se constituye como la sumatoria de un conjunto de habilidades representativas en un individuo en torno a una colectividad; supone capacidades de movilización y articulación de públicos activos en el seno de la política, orientados por un capital simbólico y una serie de códigos lingüísticos compartidos entre el líder y el seguidor. Este principio supone un alto grado de subjetividad en el carisma y la emotividad en los procesos de expresión social (Collado-Campaña, Entrena-Durán y Jiménez-Díaz, 2016).

Desde una visión de la comunicación política, la figura del líder discrepa de un rol de 'jefe' con capacidades autoritarias y delegativas, en tanto se articula a sus grupos de movilización en el seguimiento de objetivos no propios, sino comunes. El liderazgo otorga una cara a una visión colectiva de realidad (Collado-Campaña, Entrena-Durán y Jiménez-Díaz, 2016) como principio articulador de preceptos del carisma y la emotividad y eje movilizador de públicos deliberativos en la sociedad (Deusdad, 2003), a lo cual se suman las particularidades del emisor (posición política, económica y popularidad). De esta forma, "si bien, en esencia, el carisma es irracional, todo carisma tiene un componente de racionalidad. No se puede decir que sea del todo irracional, pues ordena el mundo, lo explica a los seguidores del líder político" (p. 11). En esta relación dialéctica, se evidencia un mayor grado de participación ciudadana en los procesos de transformación social, bajo el acercamiento de la figura del líder a sus seguidores y la comprensión de primera mano de sus necesidades, lo que aplica a la consolidación del conjunto de códigos comunicativos y de organización de estos grupos (Ruiloba, 2014). 
En América Latina, han surgido líderes populistas y carismáticos que han marcado tendencia al establecer interconexión efectiva con sus seguidores, partiendo de la empatía y las emociones en la construcción de sus discursos políticos. Como ejemplos de esta premisa se sitúa a Juan Domingo Perón, Rómulo Betancourt (líder carismático) y otros actores de la región (Chirinos, León y Molero, 2011). La articulación y apropiación de terminologías con altas cargas de significación social (por ejemplo 'oligarquía' y 'pueblo)' permite generar empatía y solidaridad entre el político y la audiencia, direccionando un clamor popular y un sentido de mayor pertenencia y de participación ciudadana. Si bien este factor de articulación social discursiva no aplica estrictamente a los líderes de izquierda, en esta tendencia política existe un sentido pragmático de mayor cercanía social (Chirinos, León y Molero, 2011). En retrospectiva, en el caso específico del Ecuador, este país tuvo líderes populistas o neopopulistas, entre ellos Velasco Ibarra, líder de izquierda; Abdalá Bucaram, quien apeló a los pobres en su discurso (Donoso y Moreano, 2006). Frente a esto, un contexto más reciente, se destaca el liderazgo de Rafael Correa, relevante por la adopción de discursos anti-neoliberales y una redefinición del concepto de democracia por parte de un político considerado como outsider, más por su condición de vinculación a la academia. Este líder, destacó por su capacidad de articulación discursiva con la sociedad:

Correa cumpliría con las características del populista surgido de una élite académica con un discurso anti-establecimiento, una masa que lo acompaña identificada con sus decisiones desde el ministerio de economía que pretende materializar lo que Di Tella llama una "revolución de aspiraciones" y finalmente una ideología fuertemente emocional (Jaramillo-Jassir 2012, p. 148).

El liderazgo político requiere que la figura que encamina un proceso de movilización social sea capaz de articular a los públicos que comparten sus principios de expresión social, lo que aplica a una base de carisma que cautive y facilite la guía hacia un fin común. Ello amerita que los seguidores del líder se tornen agentes sociales activos de cambio y diferenciación. En tal sentido, se sustancia el análisis de los discursos del Ecuador en el período 2007-2016, regido bajo mandatos de Rafael Correa, líder fuertemente carismático. Si bien en algunos casos él no será el enunciador, sus delegados partirían de una línea de gobierno que responde a una agenda política predefinida.

\subsection{Discurso, poder y contra-hegemonía}

Como base de este apartado, se hilan los conceptos de discurso y poder, partiendo de la posibilidad de establecer procesos de dominación con el empleo del discurso como espacio de reconstrucción de simbolismos sociales, emitidos desde espacios de enunciación de constructos de forma sólida e influyente. En este orden, el discurso como base del ejercicio de la dominación y del poder, no parte de la generación de enunciados aislados, sino que el lenguaje es mediado y soportado por un conjunto de configuraciones exógenas a la palabra, entre ellas el contexto y los elementos que otorguen fortaleza al enunciante sobre el oyente (Van Dijk, 2009).

Habermas (1994) visualiza a la opinión pública como un fenómeno regido desde una esfera burguesa, compuesta por individuos con capacidad de raciocinio y con la atri- 
bución de toma de decisiones que impliquen a los sectores de la sociedad. Este autor circunscribe a todo lo ajeno a este contexto burgués delimitado como 'opinión no pública' que no presenta capacidad de transformación del contexto de la política y la economía. Si se perfila esto desde una perspectiva de dominación tiene lugar la concepción gramsciana de hegemonía, vista como el conjunto de conceptos o categorías dominantes frente a otras que permanecen secundarias o eclipsadas. Esta supone la superposición de preceptos lógicos de relaciones sociales que se enmarcan en una conexión macro de relaciones internacionales donde convergen intereses compartidos en los que buscan ser adheridos (al menos en un modo dialéctico) los sectores dominados de la sociedad (Gramsci, 1975). El concepto es clave para pensar y repensar el modo de hacer política, partiendo de que el "poder se definía por el grado de consenso que obtenía de las masas populares a las que dominaba, y la consiguiente reducción en la cantidad de coerción necesaria para reprimirlas" (Giacaglia, 2002, p. 153). Por sí solo, el discurso no legitima una visión hegemónica, en tanto en este proceso se articulan instituciones educativas, eclesiásticas, comunicacionales (entre otras) para transmitir pautas de conducta continuamente a las masas receptoras. Una visión gramsciana del concepto de hegemonía supone la "dirección política, intelectual y moral" (p. 153), por parte de estructuras coercitivas de la capacidad crítica del desarrollo del pensamiento ideológico.

Este concepto se vincula a un precepto dominante, elitista y burgués de la opinión pública (Habermas, 1994), frente a lo cual surgen visiones más contemporáneas que sustentan la idea de posibilidades discursivas frente a estos espacios de dominación, por ejemplo el concepto de contra-públicos subalternos (Fraser, 1997), que señala que, frente a espacios de dominación por parte de sectores de la élite política y económica, existe la posibilidad de presenciar pequeños espacios de deliberación vistos como espacios de contrapoder, como discursos alternativos a los dominantes y que pueden replegarse en espacios y procesos de disputa de forma sostenida. En este contexto, desde finales del siglo XX, se presenció la reconfiguración de órdenes políticos y sociales desde el surgimiento de contra-discursos 'revolucionarios' frente a formas de hacer política 'de manual' y fue la articulación de estructura de poder social desde contra-públicos subalternos lo que para Latinoamérica supuso repensar el modo de hacer política con un Estado que se articula con la sociedad civil (De Sousa Santos,2010) y en un nivel internacional a través de organismos como CELAC y la ALBA (Barrenengoa, 2017).

\section{Metodología}

El estudio parte de metodología mixta, la cual supone la interconexión de los preceptos metodológicos cuantitativos y cualitativos, con el fin de profundizar en el objeto de estudio y generar hallazgos que no podrían lograrse con solo uno de los métodos. Para Hernández, Fernández y Baptista (2014), "los métodos mixtos utilizan evidencia de datos numéricos, verbales, textuales, visuales, simbólicos y de otras clases para entender problemas en las ciencias" (p. 534).

Como segundo aspecto metodológico a considerar, se parte el método comparado y analítico "que distingue las partes de un todo y procede a la revisión ordenada de cada uno de los elementos por separado" (Gutiérrez \& González, 1990, p. 133). El enfoque del estudio es de tipo cualitativo y descriptivo: mientras el primero permitirá desfragmentar la 
información de forma analítica en base a hechos y no a datos numéricos (Baptista, Fernández, \& Sampieri, 2014), el segundo permitirá investigar con precisión y sin propuestas de cambio los ángulos y dimensiones de un fenómeno, suceso, situación o comportamiento en un determinado contexto (Monje, 2011). Dentro del enfoque cualitativo se utiliza el Análisis de Discurso como técnica que permite analizar el contenido semántico de conceptos que utilizan determinados actores (Sayago, 2015) teniendo en cuenta que el Análisis Crítico de Discurso no se constituye a priori como una metodología, sino que incorpora una serie de elementos derivados de la investigación cualitativa para comprender las relaciones de poder manifiestas a través de los discursos de figuras con capacidad de movilizar ideológicamente grupos sociales. En cuanto al objetivo general y a los objetivos específicos, el estudio se propone:

Analizar los discursos realizados por Ecuador en el marco de la Asamblea General de la Organización de Naciones Unidas durante el periodo 2007-2016, identificando las principales categorías discursivas propuestas por este país desde la perspectiva de contra-hegemonía.

Identificar las características y construcciones discursivas de los actores políticos ecuatorianos en el marco de la Asamblea General de la Organización de Naciones Unidas durante el periodo 2007-2016.

Analizar las temáticas principales abordadas por Ecuador en el marco de la Asamblea General de la Organización de Naciones Unidas.

Para el análisis de los discursos de Ecuador -2007-2016- en la ONU, se seleccionaron los emitidos en el marco de la Asamblea General. El periodo totaliza 10 discursos oficiales. Esta delimitación temporal permite observar temas de agenda de la política exterior ecuatoriana y la forma cómo se transmite el mensaje comunicacional.

Tabla 1. Discursos del Ecuador en la ONU

\begin{tabular}{|c|c|c|c|}
\hline AÑO & Datos de la conferencia/discurso & Actor que realiza el discurso & Extensión del discurso \\
\hline 2007 & $\begin{array}{l}62^{\circ} \text { Periodo de sesiones de la } \\
\text { Asamblea General de Naciones } \\
\text { Unidas } \\
\text { (26 de septiembre, } 2007)\end{array}$ & $\begin{array}{l}\text { Rafael Correa } \\
\text { Presidente de Ecuador }\end{array}$ & 1554 palabras \\
\hline 2008 & $\begin{array}{l}63^{\circ} \text { Periodo de sesiones de la } \\
\text { Asamblea General de Naciones } \\
\text { Unidas } \\
\text { (29 de septiembre, } 2008)\end{array}$ & $\begin{array}{l}\text { María Fernanda Espinosa } \\
\text { Representante permanente de } \\
\text { Ecuador ante la ONU }\end{array}$ & 2200 palabras \\
\hline
\end{tabular}




\begin{tabular}{|c|c|c|c|}
\hline 2009 & $\begin{array}{c}64^{\circ} \text { Periodo de sesiones de la } \\
\text { Asamblea General de Naciones } \\
\text { Unidas } \\
\text { (28 de septiembre, 2009) }\end{array}$ & $\begin{array}{l}\text { Fander Falconí } \\
\text { Ministro de Relaciones Exteriores }\end{array}$ & 3081 palabras \\
\hline 2010 & $\begin{array}{c}65^{\circ} \text { Período de Sesiones de la } \\
\text { Asamblea General de Naciones Unidas } \\
\text { (28 de septiembre, } 2010)\end{array}$ & $\begin{array}{c}\text { Lenín Moreno Garcés } \\
\text { Vicepresidente de Ecuador }\end{array}$ & 1453 palabras \\
\hline 2011 & $\begin{array}{c}66^{\circ} \text { Período de Sesiones de la } \\
\text { Asamblea General de Naciones Unidas } \\
\text { (27 de septiembre, } 2011)\end{array}$ & $\begin{array}{l}\text { Francisco Carrión Mena } \\
\text { Representante permanente de } \\
\text { Ecuador ante la ONU }\end{array}$ & 2917 palabras \\
\hline 2012 & $\begin{array}{c}67^{\circ} \text { período de Sesiones de la } \\
\text { Asamblea General de Naciones } \\
\text { Unidas } \\
\text { (1 de octubre, } 2012)\end{array}$ & $\begin{array}{c}\text { Marco Albuja } \\
\text { Viceministro de Relaciones } \\
\text { Exteriores }\end{array}$ & 3875 palabras \\
\hline 2013 & $\begin{array}{c}68^{\circ} \text { periodo de Sesiones de la } \\
\text { Asamblea General de Naciones } \\
\text { Unidas } \\
\text { (1de octubre, } 2013)\end{array}$ & $\begin{array}{c}\text { Xavier Lasso Mendoza } \\
\text { Representante permanente de } \\
\text { Ecuador ante la ONU }\end{array}$ & 1633 palabras \\
\hline 2014 & $\begin{array}{l}69^{\circ} \text { período de sesiones de la } \\
\text { Asamblea General de Naciones Unidas } \\
\text { (30 de septiembre, } 2014)\end{array}$ & $\begin{array}{c}\text { Leonardo Arízaga } \\
\text { Viceministro de Relaciones } \\
\text { Exteriores e Integración Política }\end{array}$ & 3415 palabras \\
\hline 2015 & $\begin{array}{c}70^{\circ} \text { período de sesiones de las } \\
\text { Naciones Unidas, }(28 \text { de septiem- } \\
\text { bre, } 2015)\end{array}$ & $\begin{array}{c}\text { Rafael Correa } \\
\text { Presidente de Ecuador }\end{array}$ & 2446 palabras \\
\hline 2016 & $\begin{array}{c}71^{\circ} \text { período de sesiones de las } \\
\text { Naciones Unidas, Nueva York } \\
\text { (23 de septiembre, 2016) }\end{array}$ & $\begin{array}{c}\text { Guillaume Long } \\
\text { Ministro de Relaciones } \\
\text { Exteriores y Movilidad Humana }\end{array}$ & 1899 palabras \\
\hline
\end{tabular}

Fuente: elaboración propia 
Se diseñó e implementó una ficha de observación ad hoc adaptada al objeto de estudio, con la que se extraen los datos necesarios para la investigación, con los siguientes ítems:

Tabla 2. Ficha ad hoc

\begin{tabular}{|c|c|c|c|c|c|}
\hline $\begin{array}{c}\text { Actor que } \\
\text { realiza el } \\
\text { discurso }\end{array}$ & $\begin{array}{l}\text { Exten- } \\
\text { sión del } \\
\text { discurso }\end{array}$ & Enfoque del tema Principal & $\begin{array}{c}\text { Enfoque } \\
\text { del tema } \\
\text { secundario }\end{array}$ & $\begin{array}{l}\text { Lenguaje } \\
\text { del actor }\end{array}$ & Enfoque del discurso \\
\hline $\begin{array}{l}\text { 1. Rafael } \\
\text { Correa } \\
\begin{array}{l}\text { 2. Can- } \\
\text { ciller }\end{array} \\
\text { 3. Otro }\end{array}$ & $\begin{array}{l}\text { Número de } \\
\text { Palabras/ } \\
\text { Tiempo }\end{array}$ & $\begin{array}{l}\text { 1. Política } \\
\begin{array}{l}\text { 2. Ambiente/medio } \\
\text { ambiente }\end{array} \\
\text { 3. Educación } \\
\text { 4. Social } \\
\text { 5. Salud } \\
\text { 6. Otro }\end{array}$ & $\begin{array}{l}\text { 1. Política } \\
\begin{array}{l}\text { 2.Ambi- } \\
\text { ente/medio } \\
\text { ambiente }\end{array} \\
\begin{array}{l}\text { 3.Edu- } \\
\text { cación }\end{array} \\
\text { 4. Social } \\
\text { 5. Salud } \\
\text { 6. Otro }\end{array}$ & $\begin{array}{l}\text { 1. Formal } \\
\text { 2. Infor- } \\
\text { mal }\end{array}$ & $\begin{array}{l}\text { 1.Positivo } \\
\text { 2.Negativo } \\
\text { 3.Neutro }\end{array}$ \\
\hline $\begin{array}{r}\text { Carac } \\
\text { discursiv }\end{array}$ & $\begin{array}{l}\text { rísticas } \\
\text { del actor }\end{array}$ & $\begin{array}{l}\text { Identificación de adve } \\
\text { (políticos o económ }\end{array}$ & $\begin{array}{l}\text { rsarios } \\
\text { (cos) }\end{array}$ & Cons & ucciones Discursivas \\
\hline \multicolumn{2}{|c|}{ 5. Informativo } & $\begin{array}{r}\text { 1. EEUU } \\
\text { 2. Colombia } \\
\text { 3. Transnacionale } \\
\text { 4. Organismos internacionale } \\
\text { 5. Organismos region } \\
\text { 6. Medios de comunica } \\
\text { 7. Élite política } \\
\text { 8. Élite empresaria }\end{array}$ & $\begin{array}{l}\text { financieros } \\
\text { iones }\end{array}$ & $\begin{array}{r}\text { 1. R } \\
\text { 2.So } \\
4 . \\
\text { 5. Cr } \\
\text { 8. Nue } \\
\text { 12 } \\
\text { 14. D }\end{array}$ & $\begin{array}{l}\text { evolución Ciudadana } \\
\text { cialismo del Siglo XXI } \\
\text { 3. Buen Vivir } \\
\text { Ecologismo infantil } \\
\text { ítica a multinacionales } \\
\text { 6. Deuda social } \\
\text { 7. Neoliberalismo } \\
\text { a arquitectura financiera } \\
\text { 9. Patria Grande } \\
\text { 0. Multipolaridad } \\
\text { 11. Hegemonía } \\
\text { Contra-hegemonía } \\
\text { 13. Yasuní ITT } \\
\text { emocracia Participativa } \\
\text { 15. Pachamama }\end{array}$ \\
\hline
\end{tabular}

Fuente: elaboración propia 
Actor que realiza el discurso: identifica al actor que realiza el discurso

Extensión del discurso: contabiliza el número de palabras de cada discurso.

Lenguaje del actor: diferencia entre lenguaje formal e informal.

Enfoque del discurso: distingue entre positivo, negativo (o crítico) y neutro.

Construcciones discursivas: se identifican 15 construcciones o categorías discursivas que son base de los documentos programáticos de Ecuador a partir de 2007.

\section{RESULTADOS Y DISCUSIÓN}

\subsection{Actor principal}

De los 10 discursos emitidos dentro de la Asamblea General de la ONU en el periodo de estudio, Rafael Correa figura en dos ocasiones (20\%) en los años 2007 y 2015 y el vicepresidente Lenin Moreno en una ocasión (10\%). El resto de discursos fueron realizados por representantes del Estado en el ámbito de la política exterior: cancilleres (20\%), representante permanente de Ecuador ante Naciones Unidas (30\%) y viceministros de relaciones exteriores $(20 \%)$ tal y como se muestra:

\section{Gráfico 1. Actor que realiza el discurso}

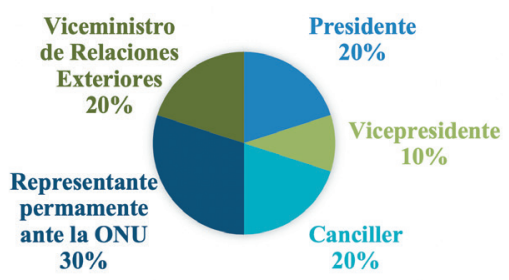

Fuente: base de datos

El actor principal está estrechamente ligado a la forma de abordaje del discurso, en tanto se evidenció en el caso del Rafael Correa mayor grado de criticidad en su discurso al tener más libertad enunciativa y al figurar como la representación máxima del Estado. Frente a este, las figuras políticas delegadas estaban enmarcadas dentro de una estructura discursiva más formal y restringida. En cuanto a la extensión del discurso, el mínimo tiene una extensión de 1453 palabras (a cargo de Lenin Moreno en 2010) y el máximo 3876 palabras (por Marco Albuja). El promedio oscila entre 1501 y más de 3000 palabras.

\section{Gráfico 2. Extensión del discurso}

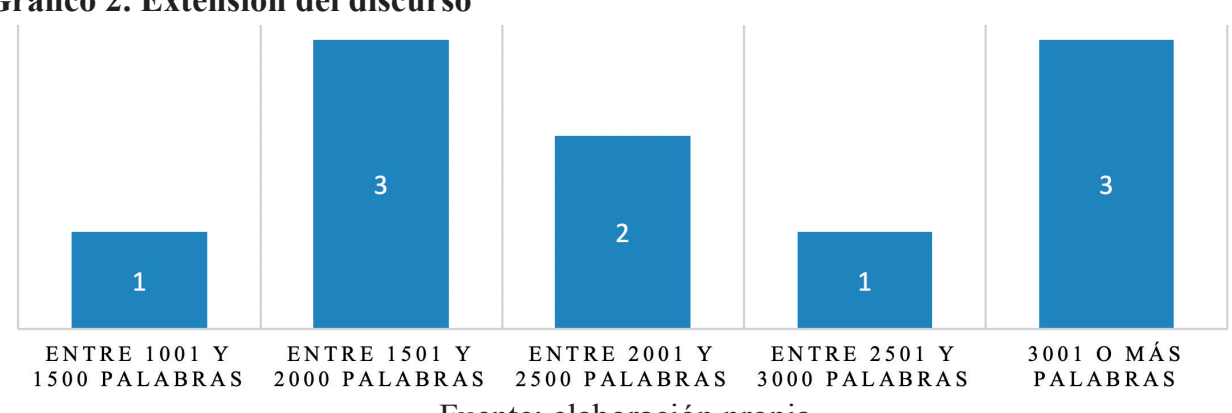

Fuente: elaboración propia 


\subsection{Enfoque del tema principal y secundario}

El enfoque del tema principal muestra un predominio del ítem 1. Política (60\%), seguido de los ítems, 4. social y 2 . ambiente o medio ambiente con un $30 \%$ y $10 \%$ respectivamente. Las temáticas específicas asociadas a 1. política, tienen que ver con la propuesta de crear nuevos espacios multilaterales como ALBA y UNASUR; la reestructuración del sistema financiero y una nueva arquitectura financiera para América Latina; la refundación del sistema de Naciones Unidas bajo un esquema más democrático y justo para todos los Estados en condiciones de igualdad (temática presente en la mayoría de los discursos) a través de una reforma al consejo de seguridad y; un "Pacto ético" en alternativa al "capitalismo especulativo y la plutocracia global".

\section{Gráfico 3. Enfoque del tema principal y secundario}

\section{Enfoque del tema principal}

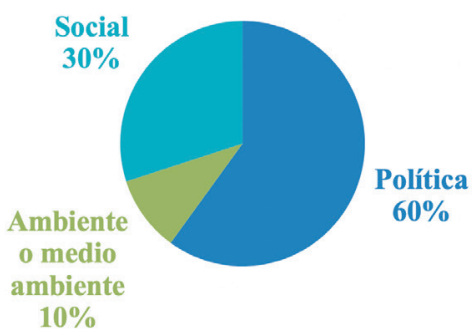

\section{Enfoque del tema secundario}

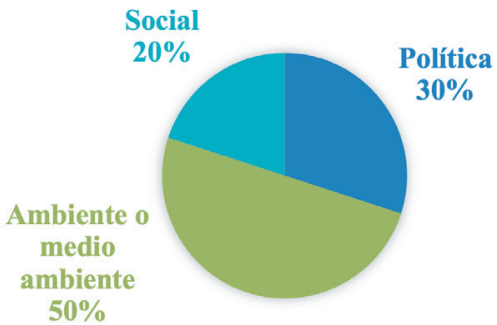

Fuente: elaboración propia

En el segundo enfoque principal se identifica: 4. Social, donde Ecuador expone los principales avances en cuanto a desarrollo: reducción de la desigualdad, desempleo, pobreza general y pobreza extrema, dando énfasis en 2008 y 2009 a los Objetivos del Milenio y más tarde a los Objetivos de Desarrollo Sostenible. Este espacio es utilizado para mostrar resultados del modelo social implementado por la Revolución Ciudadana en políticas públicas de educación, salud y migratorias (ciudadanía universal, derechos de los ecuatorianos emigrantes y de las personas en movilidad humana). Se debe destacar que este enfoque tiene primacía en los dos discursos emitidos por Rafael Correa.

El último enfoque principal en importancia es el 2. Ambiente o medio ambiente, en el año 2010 por Lenín Moreno (vicepresidente), quien hace énfasis en el Proyecto Yasuní ITT (presentado en la ONU desde 20017) en el cual, Ecuador renuncia a la explotación petrolera de las zonas de Ishpingo, Tiputini y Tambococha, a cambio de una contribución económica de al menos la mitad de lo que representaría su explotación por parte de la comunidad internacional. Cabe acotar que, este ítem es enfoque del tema secundario en 50\% de los discursos que insisten en la propuesta del Yasuní ITT, y al mismo tiempo exponen el daño causado por las petroleras transnacionales en la selva amazónica ecuatoriana. La 1. Política por su parte, es tema secundario en el 30\% con aspectos relacionados con temas de la agenda de política exterior como la integración Sur-Sur, crítica a Naciones Unidas y otras de coyuntura como el asilo político de Julian Assange. 


\subsection{Características discursivas del actor, características y enfoque del discurso}

Dentro de este segmento, se evidencian diferencias entre las características del actor que tiende a ser crítico (8 de 10) y las características del discurso que si bien, tiende a ser crítico (6 de 10) se presenta en un $40 \%$ como neutral. Aunque se presenta el discurso en un contexto de representación política formal, el relato es presentado con características discursivas del actor en clave crítica. En este orden, se utiliza el propio espacio de la Organización de Naciones Unidas para realizar cuestionamientos y propuestas de reforma y democratización. Por su parte, la neutralidad se manifiesta en mayor medida si se analiza el lenguaje como un elemento aislado.

\section{Gráfico 4. Características discursivas}

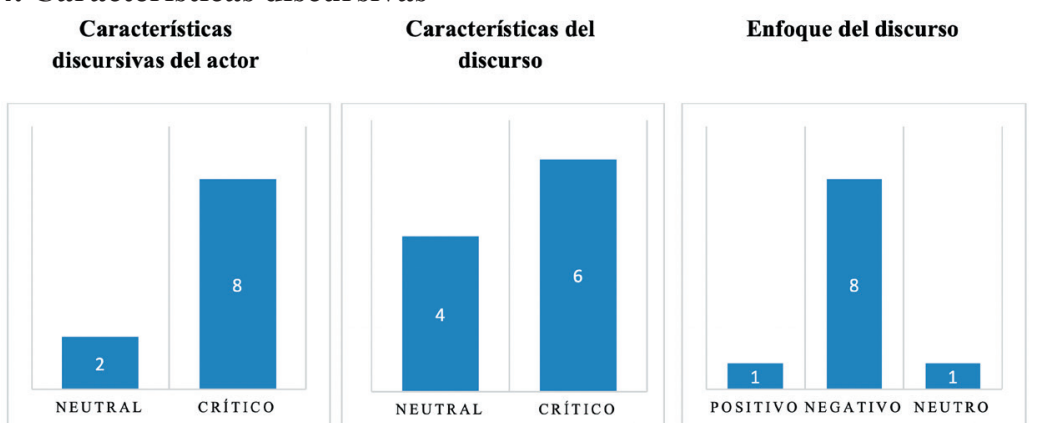

Fuente: elaboración propia

Finalmente, el enfoque general del discurso es de carácter negativo (crítico), tomando en consideración la realidad concerniente al espacio de enunciación. Se toma al discurso como un todo, en lo cual se identifica que su carácter predominantemente crítico se vincula 1.- a la construcción de un relato de política exterior distinto y vinculado a la ideología predominante en América Latina (izquierda); 2.- a las políticas sociales de Ecuador y; 3.- a la impronta verde de su Constitución (derechos de la tierra) que da fuerza al reclamo de falta de compromiso de la comunidad internacional con el medio ambiente y el cambio climático.

\subsection{Identificación de adversario político}

De los 10 discursos analizados, 7 identifican a uno o varios adversarios políticos, mientras que 3 de ellos no lo hacen manera expresa, específicamente los casos de María Fernanda Espinosa, Lenin Moreno y Marco Albuja. Estados Unidos se presenta como el principal adversario, al ser considerada potencia hegemónica.

\section{Gráfico 5. Identificación de adversario político}

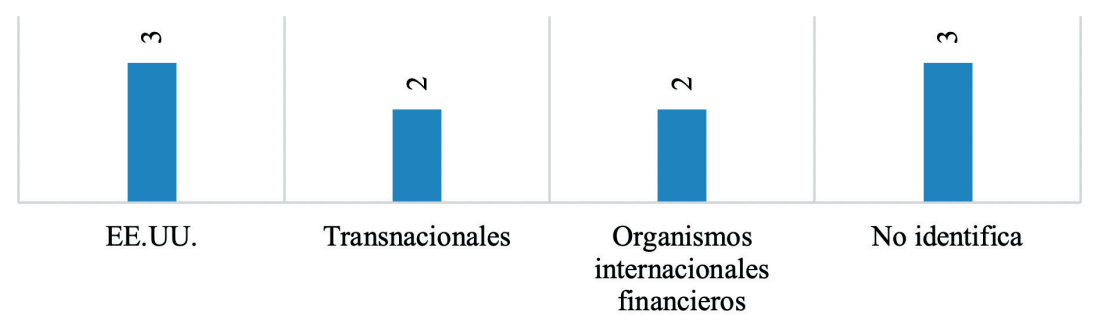


Gráfico 6. Adversario político específico (transnacionales y organismos internacionales financieros)

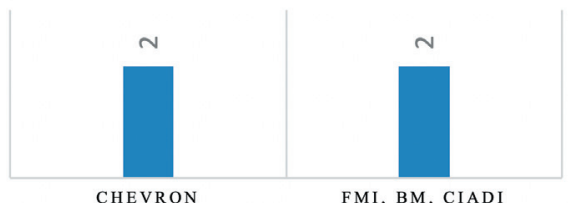

Fuente: elaboración propia

Por su parte, en los dos discursos donde se vinculan a las transnacionales como adversario, se relaciona a estas de manera específica con Chevron. Esto se une al enfoque de los temas ambientales en tanto se presenta de manera reiterada su efecto negativo en los territorios ecuatorianos en los que intervinieron, el proyecto del Yasuní ITT y la campaña "Mano sucia de Chevron", adelantada por el gobierno de la Revolución Ciudadana. Aquellos casos en los que se tratan a los Organismos Internacionales Financieros como adversarios, estos se relacionan puntualmente con la estructura económico-financiera del Bretton Woods: Fondo Monetario Internacional y Banco Mundial. Esta contraposición se genera en el contexto de la conformación de una comisión para el estudio de la deuda externa ecuatoriana que recibió el gobierno de Rafael Correa en su llegada al poder. Adicionalmente, el CIADI es mencionado como adversario en el discurso de 2009 de Fander Falconí, dadas las reclamaciones ante esta entidad de los daños causados por transnacionales petroleras en Ecuador.

\subsection{Categorías discursivas}

Este estudio identifica 15 categorías discursivas que son recurrentes en el discurso la Revolución Ciudadana:

Tabla 3. Construcciones Discursivas

Construcciones Discursivas

1. Revolución Ciudadana

2. Socialismo del Siglo XXI

3. Buen Vivir

4. Ecologismo infantil

5. Crítica a multinacionales

6. Deuda social

7. Neoliberalismo

8. Nueva arquitectura financiera

9. Patria Grande

10. Multipolaridad

11. Hegemonía

12. Contrahegemonía

13. Yasuní ITT

14. Democracia Participativa

15. Pacha Mama

Fuente: Elaboración propia 
La categoría que tiene mayor frecuencia en todos los discursos es la 14. Democracia participativa, siendo el año 2014 en el que se utilizó con más intensidad. Esta es parte fundamental de la propuesta política de Rafael Correa conjuntamente con la categoría 3. Buen Vivir que es mencionada en siete de los discursos y 6. Deuda Social, presente en 6 discursos en los que se insistió en temas relacionados a la disminución de brechas sociales y económicas. Por su parte, la 5. Crítica a multinacionales toma fuerza a partir del año 2009, cuando se insiste a la comunidad internacional sobre el proyecto del Yasuní ITT y se identifica como adversario al CIADI, FM y BM y se mantiene durante los años 2012, 2013, 2015 y 2016. Se debe destacar que, la 1. Revolución Ciudadana es referenciada desde el año 2007 por Rafael Correa, Fander Falconí (2008), Leonardo Arizaga (2014) y Guillaume Long (2016), fechas que coinciden con el inicio y fin de los mandatos de Rafael Correa. Las categorías 2. Socialismo del siglo XXI, 4. Ecologismo infantil y 12. Contra-hegemonía no presentan frecuencias en ninguno de los años, mientras que, 9. Patria Grande (2016), evidencia una sola aparición en 2016 y dos apariciones la categoría 15. Pacha Mama (2010 y 2012).

La construcción discursiva 11. Hegemonía se encuentra presente en los años 2012 y 2016, momentos en los que Ecuador identifica a Estados Unidos como adversario político y exige con más énfasis una reforma al Consejo de Seguridad del sistema de Naciones Unidas. En cuanto a la categoría 13. Yasuní ITT, su permanencia en el discurso es clara para los primeros 5 años de gobierno; es así, que, de 2007 a 2012 formó parte de los temas principales y secundarios, dada la relevancia en la agenda política de Ecuador. Una vez que este país decide abandonar esta iniciativa, la categoría desaparece del discurso en este espacio.

En lo referente a 7. Neoliberalismo se aborda en ambos discursos de Rafael Correa y también es mencionada por el entonces Canciller Guillaume Long, actores que señalan a la 10. Multipolaridad como aspecto necesario para hacer frente a la hegemonía estadounidense. La 8. Nueva arquitectura financiera se observa en 2009, 2011 (año en el que se menciona la necesidad de una reforma del sistema financiero internacional) y en 2012, coincidiendo con la propuesta de reforma al sistema de Naciones Unidas.

\section{Gráfico 7. Construcciones discursivas}

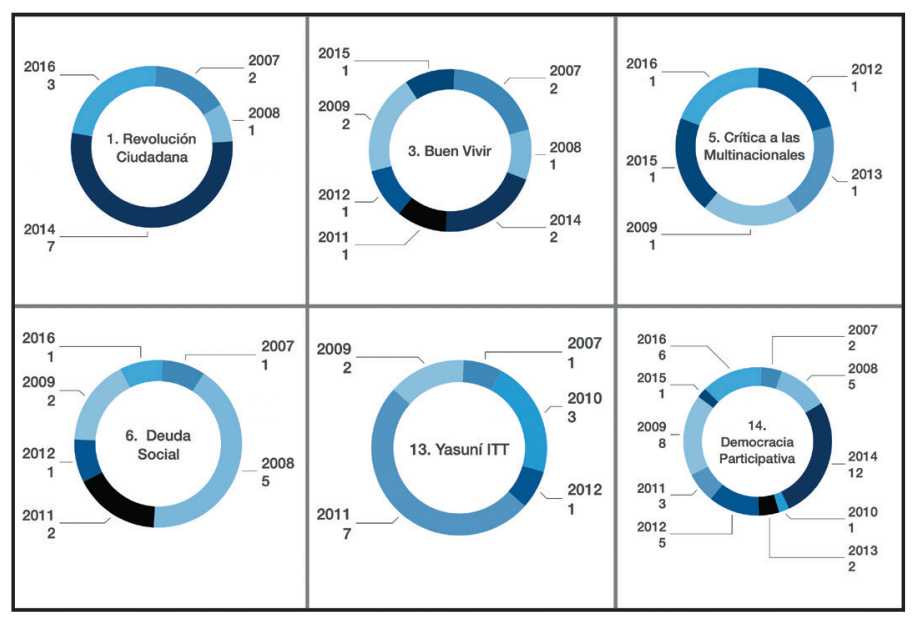


Finalmente, es preciso destacar que, en las intervenciones de Rafael Correa, sus construcciones discursivas apelaron con más intensidad a: 1. Revolución Ciudadana (2007), 3. Buen Vivir (2007 y 2015), 5. Crítica a Multinacionales (2015), 6. Deuda Social (2007), 7. Neoliberalismo (2007 y 2015), 13. Yasuní ITT (2007), 14. Democracia Participativa (2007 y 2015). Estas recogen en esencia los principales aspectos conceptuales de su gestión de gobierno y son frecuentes en los espacios de deliberación pública en los que él es emisor.

\section{CONCLUSIONES}

Tomando en cuenta los elementos característicos del liderazgo político, se partió del principio de representatividad discursiva de un Estado por parte de un actor político legitimado. Es así como, dentro de los diez discursos analizados dos de ellos fueron realizados por el entonces presidente Rafael Correa y los ochos restantes por Cancilleres, ministros y viceministros de relaciones exteriores, representantes permanentes de Ecuador ante Naciones Unidas y el vicepresidente, todos ellos agentes de política exterior. En este sentido, cada interlocutor dispuso de recursos para construir un discurso que no solo constó del uso de la palabra como elemento articulador, sino que incorporó sentidos y significaciones, y en el caso del expresidente Correa, figuró como el responsable de diseñar la agenda política exterior lo cual le otorgó mayor alcance enunciativo. De todas las intervenciones se debe destacar la coherencia entre la Constitución de Montecristi, los Planes Nacionales de Desarrollo, el Plan Nacional de Política Exterior y los temas abordados y priorizados, lo que permite notar una agenda de política exterior con objetivos, posiciones e intereses más independientes en dos niveles: 1. discursivo con issues nuevos y categorías discursivas orientadas, que son constantes y en clave de contra-hegemonía y 2. programático con planes, programas y proyectos de base social, transversal a la propia agenda de política exterior.

La orientación de todos los discursos es homogénea ya que se presentan temáticas claras que se desarrollan de manera coherente año tras año tomando como fundamento la crítica al status quo. De esta forma, los primeros discursos utilizan el espacio de la Asamblea General de Naciones Unidas como palestra para la presentación a la comunidad internacional de los proyectos más importantes a ser desarrollados por la Revolución Ciudadana, todos ellos con una marcada impronta social, política y de agenda verde (Yasuní ITT, ciudadanía universal, implementación de políticas sociales para la reducción de asimetrías, propuestas de reforma a la ONU y la creación de nuevos esquemas de integración regional). A partir de 2010 el mismo espacio es usado para presentar los resultados de esos proyectos, se sigue la misma línea argumentativa en el aspecto político y se dan acciones concretas en ese orden como el asilo político a Julian Assange.

La identificación del adversario estuvo ligado al nivel de representación política del actor que emitió los mensajes y a la temática principal del discurso. En tal sentido, tanto los adversarios políticos como los enfoques de los temas principales y secundarios se manifiestan desde una base ideológica orientada a la izquierda. Ecuador se circunscribe a un discurso integrador de las políticas latinoamericanas tomadas por países de tendencia progresista, marcando, por un lado, un hito integrador en la región y por otro un discurso de contraposición que se materializa a través de prácticas políticas anti-hegemónicas y económicas con base en el posneoliberalismo. Si bien los actores emplean lenguaje formal en sus enunciados, la 
tipología de sus intervenciones se enmarcan en contra discursos que apelaron a la emotividad de los públicos. Todo ello logró posicionar a un país pequeño como Ecuador en el ámbito de las relaciones exteriores y en los espacios multilaterales de política internacional.

\section{REFERENCIAS BIBLIOGRÁFICAS}

BARRENENGOA, A. (2017). El proceso de integración latinoamericano desde la experiencia de la UNASUR. Revista: Realidad Económica, 11-32

CHIRINOS, A.; LEÓN, F.; y MOLERO, L. (2011). El discurso político en Latinoamérica. Análisis semántico-pragmático. Quórum Académico, 11-35

COLLADO-CAMPAÑA, F., JIMÉNEZ-DÍAZ, J., y ENTRENA-DURÁN, F. (2016). El liderazgo político en las democracias representativas: propuesta de análisis desde el constructivismo estructuralista. Revista Mexicana de Ciencias Políticas y Sociales, 57-90. https://doi.org/10.1016/s0185-1918(16)30040-x

DESOUSASANTOS, B.(2010). Para descolonizarOccidente. Más allá del pensamiento abismal. CLACSO, Buenos Aires. https://doi.org/10.22201/cela.24484946e.2015.36.52606

DEUSDAD, B. (2003). El concepto de liderazgo político carismático: Populismo e identidades. Opción, 9-35.

FRASER, N. (1997). Iustitia Interrupta: Reflexiones críticas desde la "posición postsocialista”. Siglo del Hombre editores, Bogotá. https://doi.org/10.7440/res2.1998.29

GIACAGLIA, M. (2002), Hegemonía. Concepto clave para pensar la política. Tópicos. 151-159. https://doi.org/10.14409/topicos.v0i10.7430

GRAMSCI, A. (1975). El materialismo histórico y la filosofía de Benedetto Croce. Juan Pablo Editor, México

GUTIÉRREZ, R.; GONZÁLEZ, J. (1990). Metodología del trabajo intelectual. Esfinge, México

HABERMAS, J. (1994). Historia y Crítica de la Opinión Pública. Gustavo Gili, México D.F.

HERNÁNDEZ, R., FERNÁNDEZ, C., \& BAPTISTA, P. (2014). Metodología de la Investigación. México: McGraw-Hill / Interamericana editores, S.A.

JARAMILLO-JASSIR, M. (2012). Populismo y consolidación democrática en el gobierno de Rafael Correa ¿Dos conceptos irreconciliables? Reflexión Política, 142-153

MONJE, C. (2011). Metodología de la investigación cuantitativa. Guía didáctica. Universidad Surcolombiana. Neiva 
PARDO, A. (2012). Análisis crítico del discurso: Conceptualización y desarrollo. Cuadernos de Lingüística Hispánica, 41-62

RUILOBA, J. (2014) ¿Es el gobierno local un nuevo espacio para la participación ciudadana? El punto de vista de los alcaldes. El caso español. FLACSO Ecuador

SAGAYO, S. (2014). El análisis del discurso como técnica de investigación cualitativa y cuantitativa en las ciencias sociales. Cinta de Moebio, 1-10. https://doi.org/10.4067/s0717$554 \times 2014000100001$

SERBIN, A., MARTÍNEZ, L., y RAMANZINI, H. (2012). El regionalismo "postliberal" en América Latina y el Caribe: Nuevos Actores, nuevos temas, nuevos desafíos. Ciudad Autónoma de Buenos Aires: Coordinadora Regional de Investigaciones Económicas y Sociales (CRIES)

VALENCIA, C. (2011). Del Análisis crítico del Discurso y las Ideologías. Forma y Función, 145-169

VAN DIJK, T. (1999). El análisis crítico del discurso. Anthropos, 22-36

VAN DIJK, T. (2009). Discurso y Poder. Gedisa Editorial, Barcelona

VAN DIJK, T. (2016). Estudios Críticos del Discurso: Un enfoque sociocognitivo. Discurso \& Sociedad, 137-16

ZEPEDA, B. y EGAS, M. (2011). La política exterior de la revolución ciudadana: opinión y actitudes públicas. Mexicana de Política Exterior, 95-134 